\title{
Pathogenicity of Ichthyophonus hoferi for laboratory-reared Pacific herring Clupea pallasi and its early appearance in wild Puget Sound herring
}

\author{
R. M. Kocan ${ }^{1, *}$, P. Hershberger ${ }^{1}$, T. Mehl ${ }^{1}$, N. Elder ${ }^{2}$, M. Bradley ${ }^{2}$, \\ D. Wildermuth ${ }^{3}$, K. Stick ${ }^{3}$
}

\begin{abstract}
${ }^{1}$ School of Fisheries, University of Washington, Box 355100, Seattle, Washington 98195, USA
${ }^{2}$ USGS-BRD, Marrowstone Island Marine Station, 616 Marrowstone Pt. Rd, Nordland, Washington 98358, USA

${ }^{3}$ Washington Dept of Fish and Wildlife, 1702-4 Anderson Rd, Mt. Vernon, Washington 98273, USA
\end{abstract}

\begin{abstract}
Laboratory-reared pathogen-free Pacific herring were exposed to pure cultures of Ichthyophonus hoferi, and reproduced the disease seen in naturally infected fish-thus fulfilling Koch's Postulates. Pathogen-free herring used in this study were reared from artificially spawned eggs incubated in filtered, UV-sterilized seawater, eliminating the variables associated with multiple infections, which are common in wild herring. Wild free-ranging herring were captured monthly from June through October by dip net from 'herring balls' located in the northern Puget Sound. I. hoferi infections were identified in these fish soon after metamorphoses, about 4 mo post-hatch. The prevalence increased from 5 to $6 \%$ in 0 -yr fish to $24 \%$ in 1 -yr-old fish to 50 to $70 \%$ in fish over 2 yr old, with no associated increase in mortality. The route of natural transmission to wild herring was not determined, but carnivorous fish became infected and died when they were experimentally fed tissues infected with the organism. In vitro culture of tissues was the most sensitive method for identifying both clinical and subclinical infections.
\end{abstract}

KEY WORDS: Ichthyophonus Pacific herring · Clupea pallasi - Laboratory-reared herning In vitro

\section{INTRODUCTION}

Approximately 80000 tons $(60 \%)$ of spawning Pacific herring Clupea pallasi failed to return to Prince William Sound, Alaska (USA), in 1993, following which, the prevalence of Ichthyophonus hoferi in survivors reached $27 \%$, more than double that seen in previous years (Marty et al. 1998). Because both mortality and an increase in prevalence occurred closely together, it was proposed that $I$. hoferi might be responsible for the heavy loss of herring. Prior to this time I. hoferi was not recognized as a serious pathogen

\footnotetext{
•E-mail: kocan@fish.washington.edu
}

of Pacific herring, although it was known to occur in many North Pacific fishes. Conversely, epizootics of $I$. hoferi, often accompanied by mass mortality, have occurred sporadically in Atlantic herring Clupea harengus populations of the North Atlantic since 1898 (Sinderman \& Chenoweth 1993) and more recently in the North Sea and Baltic Sea (Rahimian \& Thulin 1996, Mellergaard \& Spanggaard 1997). Although there was a correlation between the prevalence of $I$. hoferi and mortalities reported in these epizootics, the pathogenicity of $I$. hoferi for herring has not been unequivocally demonstrated.

Conclusive proof that an organism is responsible for a disease requires that experimental infections of known specific-pathogen-free (SPF) host organisms be 
carried out to confirm Koch's Postulates. A study was designed to confirm the pathogenicity of Ichthyophonus hoferi for Pacific herring by rearing SPF herring and exposing them to pure cultures of $I$. hoferi. Parallel field studies were designed to track the development of the organism from its earliest appearance in 0 -yr through spawning age fish. Identification of the organism in wild fish was attempted by several different diagnostic methods, and transmission to carnivorous fish was attempted using the coast range sculpin Cottus aleuticus.

\section{METHODS}

Culture conditions for primary isolation. Ichthyophonus hoferi was cultured from heart, liver and spleen tissue of herring with visible gross lesions collected from Prince William Sound or Puget Sound, Washington (USA). Tissues were aseptically excised from infected fish and cultured in Leibovitz L-15 medium supplemented with $10 \%$ fetal bovine serum, 2 mM glutamine, $100 \mu \mathrm{g} \mathrm{ml}^{-1}$ Gentamicin, 100 units penicillin, and $25 \mu \mathrm{g} \mathrm{ml} \mathrm{m}^{-1}$ streptomicin and buffered to $\mathrm{pH} 7.2$ with $10 \mathrm{mM}$ HEPES buffer. A reference culture originally isolated from North Sea herring and maintained in culture for approximately 2 yr was supplied by Danish investigators (Spanggaard et al. 1994). Cultures were maintained at $12^{\circ} \mathrm{C}$ for 10 to $14 \mathrm{~d}$, during which time they were examined under a dissecting microscope at $100 \times$ magnification for the presence of $I$. hoferi spores and hyphae. Each culture was evaluated on different days by 2 independent observers to insure that low-level infections were not overlooked.

Laboratory-reared pathogen-free herring. SPF Pacific herring were reared from artificially fertilized eggs in filtered and UV-sterilized natural seawater (Kocan et al. 1997). SPF herring were fed marine rotifers Brachionus sp., and newly hatched Artemia sp., also reared in sterile seawater, for $90 \mathrm{~d}$ post-hatch, then fed live and frozen brine shrimp and frozen krill until they were 2 yr old. Prior to initiating the study, 5mo-old SPF fish were checked for pathogens by histologic examination, cell culture of tissues and bacterial culture. No pathogens were detected in SPF herring prior to initiating this study and for 2 yr following the study.

Wild herring. Wild 0 -yr herring ranging from 4 to 8 mo old were captured by dip net in northern Puget Sound near Port Townsend, Washington, between June and September, while juvenile $(1+)$ and adult $(2+$ and $3+$ ) herring were obtained from a local bait dealer on the day of capture. All herring were transported to the laboratory in tanks of filtered seawater aerated with pure $\mathrm{O}_{2}$ and subsequently maintained in flowing natural seawater at ambient Puget Sound temperature $\left(8\right.$ to $11^{\circ} \mathrm{C}$ ) and salinity $(27 \%$ ). Captive herring were fed frozen brine shrimp Artemia sp. and krill twice daily during the study. This same diet was fed to laboratory-reared herring for up to 2 yr without evidence of transmission of Ichthyophonus hoferi or any other pathogen.

Experimental infections in herring. Laboratoryreared herring were infected at 6 mo of age by intraperitoneal (IP) injection of 1000 Ichthyophonus hoferi cells of various stages and sizes at a final injection volume of $0.1 \mathrm{ml}$. Following exposure, the herring were maintained in flowing filtered seawater tanks at ambient Puget Sound temperature and salinity. Tanks were observed daily and moribund or dead fish were removed for necropsy and in vitro culture. The study was terminated when mortality reached $90 \%$. The remaining fish were euthanized with an overdose of MS-222, necropsied and examined for the presence of 1. hoferi.

Ichthyophonus hoferi prevalence in wild herring. I. hoferi prevalence in wild herring between 0 and $3+$ yr was determined by visually examining fish for skin lesions (e.g. sandpaper skin or ulcers) and gross lesions of internal organs; in addition, histologic examination of heart, liver and spleen and an in vitro culture of tissues were done. Tissues for histology were fixed in $10 \%$ formalin. Heart, liver and spleen were cut and 3 sections of each organ from each fish were stained with hematoxylin-eosin. Tissues for in vitro culture were aseptically removed, minced and placed into $15 \mathrm{ml}$ tubes containing $5 \mathrm{ml}$ of L-15 medium. Heart, liver and spleen from individual fish were pooled and cultured for 10 to $14 \mathrm{~d}$ at $12^{\circ} \mathrm{C}$, then examined at $100 \times$ magnification for the presence of spores and hyphae. Pilot studies demonstrated that tissues that were not culture-positive by $10 \mathrm{~d}$ would not convert if maintained for longer periods.

To evaluate the relative sensitivity of different diagnostic techniques, 1 group of 30 adult Puget Sound spawners showing no evidence of gross visceral lesions was necropsied and the heart, liver and spleen cut into 2 equal parts. Half of each organ was fixed in $10 \%$ formalin while the other half was cultured in L15 medium. Three sections from 2 different levels of each organ ( 6 sections total) were stained with hematoxylin-eosin and examined microscopically for the presence of Ichthyophonus hoferi. The cultured half of the tissue was examined for spores and hyphae at $100 \times$ magnification after $14 \mathrm{~d}$ in culture. A similar study was conducted with Prince William Sound herring, which had a high prevalence of grossly visible visceral lesions. A separate laboratory (G. Marty, Univ. of Califormia, Davis, CA) examined the histological sections of these fish, while the cultures were 
maintained and evaluated at the University of Washington (Seattle, WA).

Experimental infections in coast range sculpins. Wild coast range sculpins Cottus aleuticus were captured from Pipers Creek (Seattle, WA; October, 1995) and Issaquah creek, (Issaquah, WA; May, 1996). These were maintained at the University of Washington's School of Fisheries in flowing dechlorinated city water and fed frozen brine shrimp.

A pilot study was designed to verify the susceptibility of sculpins to infection by Ichthyophonus hoferi by injecting 3 fish IP with 130 to 550 spores recently cultured from infected herring tissues, while 2 control fish were injected IP with phosphate-buffered saline (PBS). Prior to injection, spores were washed with 3 changes of PBS to remove all traces of culture medium. The culture medium was decanted and replaced with PBS, after which the spores were allowed to settle $(1 \times g)$ for $1 \mathrm{~h}$ between washes. All fish were monitored for up to 4 mo and mortalities were necropsied and the heart, liver and spleen cultured in L-15 medium.

A second study was designed to determine whether sculpins could be infected orally with Ichthyophonus hoferi. Four sculpins from Issaquah Creek were injected IP with $2500 \mathrm{I}$. hoferi spores per fish. The internal organs of 2 of these sculpins that subsequently died were cultured for 1 mo, after which the spores were removed, rinsed in PBS and injected into 4 additional sculpins at a concentration of 360 spores per fish. The remaining 2 infected sculpins were sacrificed, their bodies minced and the infected tissues fed to 6 sculpins. The orally exposed sculpins were given a single feeding of fresh heavily infected tissues containing visible $I$. hoferi lesions, and monitored for $30 \mathrm{~d}$. As the organism was still embedded in the tissues no attempt was made to quantify the dose. Simultaneously, 4 control sculpins, housed in a separate tank, were injected with PBS and fed pieces of uninfected tissue. All 3 groups were monitored for $30 \mathrm{~d}$, at which time the first I. hoferi-exposed fish died. The remaining fish were then sacrificed and their tissues cultured in L-15.

\section{RESULTS}

\section{Laboratory-reared experimentally infected herring}

The Prince William Sound isolate of Ichthyophonus hoferi was pathogenic for SPF herring, infecting $90 \%$ of the fish and killing $80 \%$ within 2 mo of exposure. Fish exposed by IP injection with approximately 1000 spores began dying $7 \mathrm{~d}$ post-exposure with a meanday-to-death of $36 \mathrm{~d}$. By $56 \mathrm{~d}$ post-exposure 8 of 10 fish were dead and the study was terminated (Table 1). Gross and histologically visible lesions on the heart, liver and spleen first appeared on Day 11 post-exposure, while large spores (150 to $190 \mu \mathrm{m}$ ) were observed just under the skin $36 \mathrm{~d}$ post-exposure. These spores appeared to migrate through the body musculature to the skin, where by $46 \mathrm{~d}$ post-exposure they eroded through the skin, ruptured and presumably released their spores into the surrounding water. After the spores ruptured, dark pigmented ulcers remained in the skin where spores had originally occurred.

In vitro culture of heart, liver and spleen resulted in $90 \%(9 / 10)$ of the SPF fish culturing positive for Ichthyophonus hoferi. One fish surviving until $56 \mathrm{~d}$ post-exposure showed no signs of infection by any of the diagnostic methods employed.

No mortality was observed in a second group of 10 SPF herring injected IP with a North Sea herring isolate of Ichthyophonus hoferi, which had been in culture for approximately 2 yr. However, spores were observed under the skin of 2 fish; none had gross visceral lesions, one was histologically positive (1 spore seen in liver) and all were positive for $I$. hoferi by in vitro culture. None of the control (sham-injected) fish died and no signs of disease were detected in the controls when the study was terminated (Table 1).

All stages of parasite development seen in naturally infected fish were also observed in cultured tissues from infected fish. The large spores occurring under the skin and in sections of infected tissue were indistinguishable from those seen in mature cultures.

Table 1. Clupea pallasi. Experimental Ichthyophonus hoferi infection in laboratory-reared Pacific herring using 2 strains of the parasite. $\mathrm{n}=10$ fish for each treatment group. Length and weight shown as mean $( \pm \mathrm{SD})$

\begin{tabular}{|c|c|c|c|c|c|c|c|c|}
\hline & \multirow{2}{*}{$\begin{array}{l}\text { Mean day } \\
\text { to death }\end{array}$} & \multirow{2}{*}{$\begin{array}{c}\text { Mortality } \\
(\%)\end{array}$} & \multirow{2}{*}{$\begin{array}{l}\text { Length } \\
\text { (mm) }\end{array}$} & \multirow{2}{*}{$\begin{array}{l}\text { Weight } \\
\text { (g) }\end{array}$} & \multicolumn{2}{|c|}{ Gross lesions (\%) } & \multirow{2}{*}{$\begin{array}{c}\text { Histologically } \\
\text { positive }(\%)\end{array}$} & \multirow{2}{*}{$\begin{array}{c}\text { Positive } \\
\text { cultures }(\%)\end{array}$} \\
\hline & & & & & Skin & Viscera & & \\
\hline Controls & $--^{\mathrm{a}}$ & 0 & $82.2( \pm 8.6)$ & $5.76( \pm 1.3)$ & 0 & 0 & 0 & 0 \\
\hline Danish strain & $-{ }^{a}$ & 0 & $85.0( \pm 7.5)$ & $6.10( \pm 1.1)$ & 20 & 0 & 10 & 100 \\
\hline $\begin{array}{l}\text { Prince William } \\
\text { Sound strain }\end{array}$ & 36 & 90 & $78.8( \pm 7.0)$ & $4.52( \pm 1.2)^{\mathrm{b}}$ & 50 & 80 & 80 & 90 \\
\hline
\end{tabular}


Hyphal-like structures were evident growing from the spores by $4 \mathrm{~d}$ in culture. Microspores measuring $10 \mu \mathrm{m}$ in diameter developed at the hyphal tips and were released into the medium by $11 \mathrm{~d}$ in culture. The microspores then grew to 20 to $47 \mu \mathrm{m}$ by $15 \mathrm{~d}$, and by 3 mo were approximately $200 \mu \mathrm{m}(197.8 \pm 22.2 \mu \mathrm{m})$. These large spores appeared identical to those that began the cycle. The organism underwent a similar growth sequence in tissues obtained from freshly dead herring.

The mean weight of the SPF fish infected with the Prince William Sound strain was significantly less than that of either of the other 2 groups at the end of the study, even though they were indistinguishable at the beginning of the study ( $p=0.01, t$-test). The mean length of the Prince William Sound group was also less than that of the other 2 groups; however, the difference was not significant $(\mathrm{p}>0.05)$ (Table 1), indicating significant weight loss of infected fish during the course of the study.

\section{Wild Puget Sound herring}

Ichthyophonus hoferi was isolated from Puget Sound herring by 4 to 6 mo post-hatch (June/July), and its prevalence increased over the next $3 \mathrm{yr}$, ultimately reaching $70 \%$ (Table 2). Skin lesions were observed at approximately the same rate (4 to $6 \%)$ in all age groups from 0 to $3+y r$, suggesting a constant rate of infection (exposure), while gross visceral lesions were relatively rare, occurring primarily in fish 2 yr old and older at $\leq 5 \%$. Culture of tissues revealed a steady increase in prevalence from $6 \%$ in 0 -yr fish to $>70 \%$ in spawning adults of $3+\mathrm{yr}$. Equal numbers of spawners were examined (49 males, 51 females) and length (185 $\mathrm{mm} \pm 16.5$ and $185 \mathrm{~mm} \pm 10.9)$ and disease prevalence were not significantly different. Unlike the SPF herring, however, no difference in weight was evident between infected and uninfected wild fish, possibly reflecting a difference between clinical and subclinical infections.

\section{In vitro culture as a diagnostic tool}

In vitro culture of herring tissue proved to be more sensitive than either gross or histologic examination for detecting subclinically infected fish. Of 30 adult herring simultaneously evaluated by in vitro culture and histology, $70 \%(21 / 30)$ were positive by culture, but only $7 \%$ $(2 / 30)$ of the same fish were positive by histologic examination. Both of the histologically positive fish were also positive by in vitro culture. A similar study involving 60 spawning herring from Rocky Bay (Montague Island) in Prince William Sound showed a significant but less dramatic discrepancy between histologic examination and in vitro culture (17\% vs $28 \%$ ) (R. Kocan, Univ. of Washington, Seattle, WA, and G. Marty, Univ, of California, Davis, CA, unpubl. data). However, of the known positive Prince William Sound fish, 53\% (9/17) exhibited obvious gross lesions on their viscera, while only $6 \%(5 / 78)$ of known positive fish from Puget Sound exhibited gross lesions. This difference in severity of disease between Puget Sound fish and Prince William Sound fish may explain the difference in sensitivity of these techniques between the 2 sites.

\section{Transmission to sculpins}

The coast range sculpin proved to be susceptible to infection and disease following exposure to Ichthyophonus hoferi by IP injection of spores as well as ingestion of infected tissues. Of 3 sculpins injected IP with spores, one died 4 wk post-exposure, a second was sacrificed and the third died 3.5 mo post-exposure. All 3 presented with similar I. hoferi lesions on the heart, liver and posterior kidney and cultured positive for the organism in L-15 medium.

All 6 of the sculpins given a single feeding of infected tissue developed visible visceral lesions and died or cultured positive for Ichthyophonus hoferi within $30 \mathrm{~d}$ of exposure. None of the controls fed uninfected tissues died or cultured positive for the organism. I. hoferi was not cultured from tissues of

Table 2. Clupea pallasi. Age class differences in Ichthyophonus hoferi prevalence in wild Puget Sound herring, 1996/1997 Length and weight shown as mean $( \pm S D)$

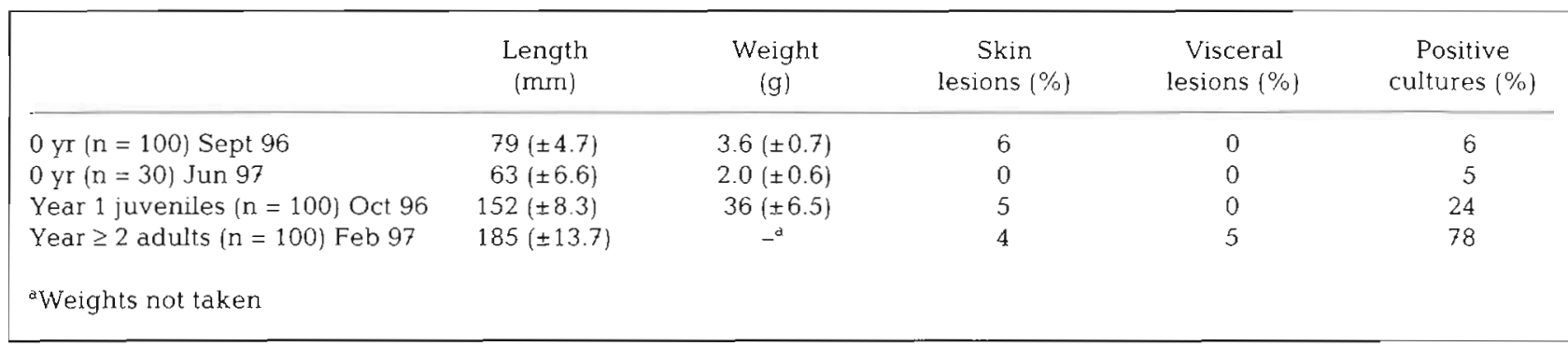


any control fish injected with PBS or fed uninfected tissues.

Since the course of the disease appeared to be the same regardless of the route of infection, injection is probably a reasonable experimental technique for studying this organism and the disease it causes in the vertebrate host.

\section{DISCUSSION}

\section{Laboratory-reared experimentally infected herring}

Ichthyophonus hoferi has been shown to be highly pathogenic for juvenile SPF Pacific herring, capable of causing extensive mortality. This confirms the causeand-effect predictions of earlier investigators that this organism is a serious pathogen of herring, capable of causing massive losses under natural conditions (Fish 1934, Sinderman \& Scattergood 1954, Sinderman \& Rosenfield 1954, McVicar 1982, Sinderman \& Chenoweth 1993). Laboratory studies serve to demonstrate the potential of an organism to cause morbidity and mortality in a host species under appropriate conditions. The actual pathogenicity in nature, however, is dependent on many variables, including multiple infections with other pathogens, nutritional status, as well as exposure to environmental contaminants.

The appearance of subcutaneous spores following infection of internal organs in IP-infected fish suggests that under natural conditions the parasite first targets the internal organs, then migrates to the skin, where it exits as small spores that may infect or be ingested by an invertebrate or larval fish. Alternatively, since herring are schooling fish and occur in high densities, the spores may directly infect individuals in close proximity to infected fish. The exact fate of the parasite after it exits the skin remains to be experimentally determined. The 'sandpaper skin' described in Atlantic herring appears to be the result of Ichthyophonus hoferi spores located under the skin. However, when these spores rupture and release their contents, their locations can still be seen as eroded holes (ulcers) in the fish's skin, but lacking the 'sandpaper' texture. This process appears to be the same in naturally infected Atlantic and Pacific herring, as well as in experimentally infected herring

Since the turn of the century, Ichthyophonus hofer has been associated with massive herring mortalities in the North Atlantic (Fish 1934, Sinderman \& Scattergood 1954, Sinderman \& Rosenfield 1954, McVicar 1982), Prince William Sound, Alaska (Meyers et al. 1994), and the North Sea and Baltic Sea (Rahimian \& Thulin 1996, Mellergaard \& Spanggaard 1997). Although the constant association of this organism with heavy mortality is highly suggestive of a causeand-effect relationship, hard evidence for this relationship was not available, and rarely did investigators look for other potential pathogens. Marty et al. (1998) describe over 10 potential pathogens associated with a massive herring disappearance in Prince William Sound, which initially appeared to be associated with an increase in prevalence in $I$. hoferi. Subsequently, viral hemorrhagic septicemia virus (VHSV), also a serious pathogen of herring (Kocan et al. 1997), was also found in these same fish, suggesting a possible alternative explanation for the massive mortality. This same virus has recently been identified from herring in the English Channel (Dixon et al. 1997). Although some field evidence for cause-and-effect may seem overwhelming, the variability associated with infection by multiple pathogens makes it essential to conduct controlled studies with pure pathogen cultures as well as SPF host animals in order to confidently assign pathogen status to a specific organism.

\section{Wild Puget Sound herring}

Wild Puget Sound herring were found to be subclinically infected with Ichthyophonus hoferi as early as 4 mo post-hatch, and exhibited a steady yearly increase in prevalence of infection with age, with rates reaching 50 to $70 \%$ by the time fish were 3 yr old. This is in contrast to Atlantic herring, where all age groups were reported to be equally infected (70\%) through winter and spring, but where infection declined to $18 \%$ in July when uninfected 'fingerlings' migrated inshore and diluted the infected population (Fish 1934). Sinderman \& Chenoweth (1993) suggest that following epizootics the prevalence drops due to mortality of infected individuals, then gradually increases until the next epizootic. A relatively low disease prevalence (average $27 \%$ ) at the epizootic peak was reported as were site prevalence rates as low as $1.3 \%$. Since there are no confirmed reports of epizootics caused by $I$. hoferi in North Pacific herring, it is not possible to determine whether the high adult prevalence observed in adult Puget Sound herring would decrease following an epizootic. The $29 \%$ prevalence reported from Prince William Sound immediately following the massive herring losses in 1993 (Marty et al. 1998 ) is similar to that reported at the peak of one epizootic in Atlantic herring (Sinderman 1958) but is much higher than that observed in Prince William Sound the previous year. This is the opposite of what Sinderman \& Chenoweth (1993) predicted following an epizootic. Multi-year surveys in Prince William Sound have shown annual changes in prevalence as well as differences in year-class prevalence (Marty et 
al. 1998). From past and present observations the prevalence rate of $I$, hoferi infection in herring populations is highly variable with no hard evidence available to account for the variability, and although 1 . hoferi infection is often associated with high mortality, no cause-and-effect relationship between $I$. hoferi prevalence and mortality has been established in wild herring. Perhaps the best way to resolve this question would be to track the prevalence rate of individual year-classes from the same geographic area over a period of years, thus focusing on temporal changes in prevalence within a single population.

The health of subclinically infected free-ranging Puget Sound herring did not appear to be different from that of uninfected fish, but relatively few wild fish exhibited heavy infections characterized by gross (visible) visceral lesions. Conversely, laboratory-reared herring experimentally infected with Ichthyophonus hoferi lost significantly more weight than their uninfected cohorts after $60 \mathrm{~d}$, but they all exhibited gross visceral lesions which appear to be indicative of terminal infections. It is possible that heavily infected freeranging herring die without being detected unless a significant epizootic occurs that kills large numbers of fish. Unlike Atlantic herring (Sinderman \& Chenoweth 1993), 0-year Puget Sound herring are infected as early as 4 mo post-hatch, prior to their inshore migration. Pelagic 'herring balls' consisting of 0 -yr herring can be found from June through October in Puget Sound, and all groups examined between 1995 and 1997 were infected with $I$. hoferi, albeit at lower levels than adult fish.

\section{Development in culture}

A predictable sequence of development similar to that observed by Okamoto et al. (1985) occurred when fish tissue infected with Ichthyophonus hoferi was placed into L-15 culture medium. Initially, large resting spores began to germinate and produce hyphae. Once hyphae developed, cytoplasm flowed into the tips where 'microspores' were produced and released into the culture medium, and ultimately developed into more large 'resting' spores. This cycle of development occurred very rapidly following culture of infected tissue, but this cycle is rarely repeated under the culture conditions used here. This suggests that this is a normal process following the death of infected fish (McVicar \& McLay 1985) and that manipulation of the culture medium is necessary to initiate a new cycle of development (Spanggaard et al. 1994). The small endospores released from hyphal tips may play a role in transmission of the organism following the death of infected host, although Okamoto et al. (1987) believe that the large multinucleated spores are the infectious stage.

\section{In vitro culture as a diagnostic tool}

The most sensitive method for identifying subclinically infected individuals is in vitro culture. Based on the differences in prevalence detected by gross visual examination and light microscopy, light microscopy appears to be more sensitive than visual examination. The use of in vitro cultivation for determining prevalence rate is supported by McVicar (1990), who noted that for infectious diseases, prevalence levels are relatively easy to determine from subsamples, ideally by direct isolation of the causative agent. Furthermore, the incidence (e.g. rate of occurrence of new cases) could be determined from frequent samples of prevalence levels in juvenile herring over a period of several months to several years, as noted in the current study. The limitation of in vitro culture is that it only gives prevalence rate but not pathogenic status or long-term prognosis

Subclinically infected fish may serve as reservoirs of infection, developing patent infections only under stress conditions that compromise the immune system (Rice et al. 1996, Tort et al. 1996). Using in vitro culture techniques, large-scale monitoring could include different age classes, geographic areas and temporal changes in prevalence of the organism. This kind of temporal and geographic data would be beneficial to managers in their decisions regarding the effects of this organism on health of fish populations.

\section{Transmission to sculpins}

The coast range sculpin proved to be a useful laboratory animal for studying Ichthyophonus hoferi transmission in the laboratory, being susceptible to both IP injection and oral exposure to infected fish tissues. Although sculpins were successfully infected with a single feeding of infected tissues, previous studies concluded that transmission only occurred in herring (Sinderman \& Scattergood 1954, Sinderman \& Chenoweth 1993) and trout (McVicar \& McLay 1985) when massive numbers of spores are fed on successive days.

The natural route of infection for herring has not been conclusively demonstrated, but there is circumstantial evidence for both direct transmission and transmission via an intermediate host (Sinderman \& Scattergood 1954, McVicar \& McLay 1985). It seems probable that herring become infected directly by free fungal spores or by eating prey items carrying an infective stage of the parasite. If an intermediate host is 
necessary for Ichthyophonus hoferi transmission to herring, epizootics might result from changes in prey selection or abundance, where more heavily infected prey become available to the herring. The wide host range and ease of transmission via contaminated food suggests that carnivory and/or scavenging of infected dead fish may play a significant role in the life cycle of I. hoferi under natural conditions.

Acknowledgements. This study was funded by the Alaska Department of Fish and Game contract IHP95-052 and the Exxon Valdez Trustee Council. Collaboration by B. Spanggaard, N. Lemberg, G. Marty, E. Brown, J. Johnson, R. Botnen and Alaska Department of Fish and Game (Cordova, AK) is appreciated.

\section{LITERATURE CITED}

Dixon P, Feist S, Kehoe E, Parry L, Stone D, Way K (1997) Isolation of viral hemorrhagic septicemia virus from Atlantic herring Clupea harengus from the English Channel. Dis Aquat Org 30:81-89

Fish FF (1934) A fungus disease in fishes of the Gulf of Maine. Parasitology 26: 1-20

Kocan R, Bradley M, Elder $N$, Meyers $T$, Batts W, Winton $J$ (1997) North American strain of viral hemorrhagic septicemia virus is highly pathogenic for laboratory-reared Pacific herring. J Aquat Anim Health 9:279-290

Marty GD, Freiberg EF, Meyers TR, Wilcock J, Farver TB, Hinton DE (1998) Viral hemorrhagic septicemia virus, Ichthyophonus hoteri, and other causes of morbidity in Pacific herring Clupea pallasi spawning in Prince William Sound, Alaska, USA. Dis Aquat Org 32:15-40

McVicar AH (1982) Ichthyophonus infections of fish. In: Roberts RJ (ed) Microbial diseases of fish. Academic Press, London, p 243-269

McVicar AH (1990) Epidemiology/epizootiology: a basis for control of disease in mariculture. In: Perkins FO, Cheng TC (eds) Pathology in marine science. Academic Press, Inc, New York, p 397-405

McVicar AH, McLay HA (1985) Tissue response of plaice, haddock, and rainbow trout to the systemic fungus Ichthyophonus. In: Ellis AE (ed) Fish and shellfish pathology. Academic Press, London, p 329-346

Editorial responsibility: David Bruno,

Aberdeen, Scotland, UK
Mellergaard S, Spanggaard B (1997) An Ichthyophonus hoferi epizootic in herring in the North Sea, the Skagerrak, the Kattegat and the Baltic Sea. Dis Aquat Org 28: 191-199

Meyers, TR, Short S, Lipson K, Batts WN, Winton JR, Wilcock J, Brown E (1994) Association of viral hemorrhagic septicemia virus with epizootic hemorrhages of the skin in Pacific herring Clupea harengus pallasi from Prince William Sound and Kodiak Island, Alaska, USA. Dis Aquat Org 19:27-37

Okamoto N, Nakase K, Suzuki H, Nakai Y, Fujii K, Sano T (1985) Life history and morphology of IChthyophonus hoferi in vitro. Fish Pathol 20:273-285

Okamoto N, Nakase K, Nakai Y, Suzuki H, Sano T (1987) Experimental oral infection of rainbow trout with cultivated spherical bodies of Ichthyophonus hoferi. Nippon Suisan Gakkaishi 53:407-409

Rahimian H, Thulin J (1996) Epizootiology of Ichthyophonus hoferi in herring populations of the Swedish west coast. Dis Aquat Org 27:187-195

Rice CD, Kergosien DH, Adams SM (1996) Innate immune function as a bioindicator of pollution stress in fish. Ecotoxicol Environ Saf 33:186-190

Sinderman CJ (1958) An epizootic in Gulf of Saint Lawrence fishes. Trans N Am Wildl Conf 23:349-360

Sindermann CJ, Chenoweth JF (1993) The fungal pathogen Ichthyophonus hoferi in sea herring Clupea harengus: a perspective from the Western North Atlantic. Int Counc Explor Sea, CM 1993/F:41 (ref Pelagic Fish Committee): $1-39$

Sinderman CJ, Rosenfield A (1954) Diseases of fishes of the Western North Atlantic: I. Diseases of the sea herring. Res Bull No. 18, Dept of Sea and Shore Fisheries, Augusta, ME, p 1-23

Sinderman CJ, Scattergood LW (1954) Diseases of fishes of the Western North Atlantic: II. Ichthyosporidium disease of the sea herring (Clupea harengus). Res Bull No. 19 Dept of Sea and Shore Fisheries, Augusta, ME, p 1-40

Spanggaard B, Gram L, Okamoto N, Huss HH (1994) Growth of the fish-pathogenic fungus, Ichthyophonus hoferi, measured by conductimetry and microscopy. J Fish Dis 17: $145-153$

Tort L, Gomez E, Montero D, Sunyer JO (1996) Serum haemolytic and agglutinating activity as indicators of fish immunocompetence: their suitability in stress and dietary studies. Aquacult Int 4:31-41

Submitted: April 7, 1998; Accepted: September 28, 1998

Proofs received from author(s): December 28, 1998 